\title{
The authorial delusion: counting lady Macbeth's children
}

Article

Accepted Version

Varotsi, L. P. (2017) The authorial delusion: counting lady Macbeth's children. New Writing: The International Journal for the Practice and Theory of Creative Writing, 14 (1). pp. 70-79. ISSN 1479-0726 doi: https://doi.org/10.1080/14790726.2016.1226342 Available at https://centaur.reading.ac.uk/68058/

It is advisable to refer to the publisher's version if you intend to cite from the work. See Guidance on citing.

To link to this article DOI: http://dx.doi.org/10.1080/14790726.2016.1226342

Publisher: Taylor \& Francis

All outputs in CentAUR are protected by Intellectual Property Rights law, including copyright law. Copyright and IPR is retained by the creators or other copyright holders. Terms and conditions for use of this material are defined in the End User Agreement.

\section{www.reading.ac.uk/centaur}

\section{CentAUR}

Central Archive at the University of Reading 
Reading's research outputs online 


\title{
The Authorial Delusion: Counting Lady Macbeth's Children
}

\begin{abstract}
:
In 1933, literary critic L.C. Knights published a caustic essay against the notion cultivated by certain of his colleagues, predominantly A.C. Bradley, that Shakespeare is a 'great creator of characters'. Knights regarded the examination of isolated particles such as 'character' as disorientating, alleging that an analysis of this sort obscures the greater merit of language. Knight's polemic essentially stands in the threshold of the dissention between formalists and realists: the former consider the examination of the fictional narrative as anything but a textual construct a scholarly faux pas; the latter regard the referential relationship between text and the world as a foundation for the creation of fiction. This is a pseudo-dilemma. The notion that literature is denuded of its artistic merit once it is defined by its constituent artifacts is disorienting, for it completely bypasses the dynamics of its creation. Put differently, a postevent analysis can exist as a standalone act, albeit it cannot challenge or dismiss the foundational principles of the event's creation process.
\end{abstract}

Key-words: Fictional Character, Creative Processes, Theory of Mind, Imaginary Dialogues, Character Construction, Creative Writing Theory

\section{Introduction}

In her work, "Why do we care about literary characters" (2010), Blakey Vermeule suggests that a reader's primary interest in the fictional character emerges as an inherent need for 'gossip', incriminating the popular, 'unsophisticated' genres in the market of endorsing reader sentimentality towards fictional characters. As she writes (2010), 
In my view, most stories are gossip literature. The distinction, so carefully cultivated by literati and academics, between high and low, between popular and polite, pales beside the overwhelming similarity of gossip literature in all media $(2010,7)$.

Vermeule's (2010, ix-x) point is explicit in her preface, where she shares her disconcertment at her students' disapproval of the character David Lurie in Coetzee's Disgrace (1999). Vermeule also dismisses any analogy between character and the real human being, claiming that this is the one "single rule of her profession that needs to be honoured" (x). Finally, she considers the metaphor of the character speaking to her author-creator as a "cliché that is passed unquestioningly among writers" $(2010,47)$.

The scholar is right to question overly emotional responses towards a non-existing entity, as they deprive the reader from the opportunity of standing critically in front of a text. The dismissal, however, of any theoretical correlation between the fictional character and the human represents a lack of understanding of both the concept, as well as the dynamics of its creation. Texts are constructed by language yet inspired by concepts, perceptual products, and the personal experiences of their originators. Those experiences reflect upon, or are drawn by, real-life interactions, even if their conveyance is purely conceptual; the correspondence to the prototype is inevitable. What may be debatable is the degree of deviation from its paradigm.

Furthermore, cognition and emotion do not stand on the two poles of an axis. Rather, they constitute the cognitive assemblage of a reader's re-constructive act. As Suzanne Keen (2006, 213) notes, “[N]arrative empathy invoked by reading must involve cognition, for reading itself relies upon complex cognitive operations"._And she expands:

In its strongest forms, aesthetics' empathy describes a projective fusing with an object which may be another person or an animal, but may also be a fictional character made of words, or even, in some accounts, inanimate things such as landscapes, artworks, or geological features. The acts of imagination and projection involved in such empathy certainly deserve the label cognitive, but the sensations, however strange, deserve to be registered as feelings. Thus I do not quarantine narrative empathy in the zone of either affect or cognition: as a process, it involves both. When texts invite readers to feel, they also stimulate readers' thinking (2006. 213).

Finally, a school of thought that dismisses significant aspects of the creative process as 'unquestioningly circulated clichés' cannot contribute to the bridging of the existing gap 
between post-event analysis and the ex-novo creation. On the contrary, narrative construction and deconstruction in synergy can enhance the learning experience.

Overall, instead of negotiating the extraction of the character concept from its referential prototype, the focus should be shifted on a theory of agent construction based on the analysis of three foundational liaisons: the concept's correlation to reality, to the reader, and to the author herself.

\section{The Author in the Obituaries}

In his work Image, music, text, Barthes (1977) declared the death of the author by contextually de-personifying the text, drawing the emphasis on the impersonality of language and rendering the (impersonal) reader the epicentre of the constructive process:

The text is a tissue of quotations drawn from the innumerable centres of culture. ... The reader is the space on which all the quotations that make up a writing are inscribed without any of them being lost; a text's unity lies not in its origin but in its destination. Yet this destination cannot any longer be personal: the reader is without history, biography, psychology; he is simply that someone who holds together in a single field all the traces by which the written text is constituted $(1977,145-148)$.

The author is essentially dissociated from her creation, thus being rendered irrelevant to

it. The text belongs to no one, it exists independent from defined subjects, and can only be decoded by a faceless decipherer - the reader. Again, the over-emphasis on language - the assemblage of semiotic symbols constructing meaningful concepts - is evident. Language is the author's tool to communicate the products of her perception and creativity. However, it is not an end in itself. As Graham MacCann writes,

Although critics often seek to justify the importance of language as a means of eliminating the aggressive authority of the human subject and its history of misdemeanours, they cannot escape this same history, and they end by erecting the edifice of language upon the tomb of the human self $(1993,77)$.

The signal cannot replace the signifier. Point in question, language itself has aided the author towards rendering her emphatic presence discreet, through tools such as the choice of 
POV. At the same time, the novelist remains the originator of this conceptual assemblage, and, whilst the reader is now recognised as an active participant in the deconstruction of textual meaning, the former cannot be banned from its circumference altogether. A. Leon Pines writes accordingly:

In language, relations and whole networks of relations are frozen into concepts labelled by words. These concepts and words capture the way a culture slices up reality: what relations are considered important enough to discriminate and preserve, what patterns and regularities have been worthwhile preserving, and so forth. ... Language serves the dual purpose of thought and communication. The ability to acquire and use language enables the amplification of meaningful experience $(1985,103-104)$.

The novelist creates, and does so by utilising and cultivating language. Symbols, hidden meanings or hypothetical intentions can only be evaluated as meta-linguistic devices without escaping their hermeneutic nature. As such, the text does not antagonise the concept; it defines and shapes it, as per the author's aims, and the reader's deconstruction, both of which can be examined within, or outside their status quo.

Returning to Vermeule's original point, an overly emotional response towards David Lurie renders him a caricature; Lurie cannot be simply loved as 'good' or hated as 'bad'. However, this is not because he is a "textual construct"; it is precisely the degree of correspondence to the real person that attributes the character in question his grandeur and depth, essentially discouraging exaggerated reactions. In fact, the constructs created to artificially serve the purposes of the aforementioned monotonous axis (good vs evil) are those prone to attracting extreme sentimentality. In such cases, the reader is no longer viewed as an active participant in the deconstruction of the text, but rather a recipient deprived from the prerogative of critical thinking and self-positioning, helpless to be saved from misdemeanors and unethical life-paths. As such, Suspension of Disbelief is compromised, for a premeditated intervention for purposes of moral didacticism will interrupt the natural flow of the narrative, abruptly extracting the reader from its textual dimensions. 
This is not to imply that literature bears no influence on society, or that novelists cannot be viewed as inspirational figures; rather, such impact should simply constitute an outcome of the reader-interpretation process. The author should strive for plausibility of character, to be established through a degree of approximation or deviation, by comparison to the prototype. The narrative's reality will merge with the reader's perception of her own reality, and any conclusions of moral substance will be drawn on a subjective level.

\section{The Author as Craftsman and Creator}

Many scholars are convinced that creating fictional worlds is an attributed gift and any attempt to apply technical principles on it is futile (Kundera, 1988; Gardner, 1983; O'Connor, 1972; Scholes and Kellogg, 1966); others contend that writing is a skill to be learnt (King, 2000; Seger, 1990; Egri, 1960). The author is regarded as either the talented artist who creates guided by her instinct alone, or as the self-made craftsman who seeks, and with practice achieves, constant amelioration.

Research on creativity (Hahn, 1968) has demonstrated that its 'trait' is observable in every individual, in different degrees. More specifically, Hahn $(1968,5)$ has indicated that, "Masterpieces in any field are usually end products, often developed after much trial and error, during which time the understanding, skills and facts necessary to achieve the objective of the creative impulse are acquired". J.P. Guildford (1959) initiated three major categories that the traits of creativity may fall under: fluency, which refers to the individual's ability to retrieve stored information from her own memory; flexibility, pertaining to her problem-solving adjustability and approach; and elaboration, which constitutes the completion of the concept with details.

In a context of creative writing pedagogy, a theory of character creation can enhance academic knowledge and practice on an inter-disciplinary, epistemological level across the 
Humanities and Social Sciences. If there is any indication that the reading of fiction can enhance social skills (Mar \& Oatley, 2008), investigating the dynamics of character-creation through diversity and multidimensional depictions can promote social understanding further. The fictional text can be viewed as an imprint of the author's consciousness on paper. Her aesthetic, emotive and perceptual abilities constitute the primary instruments at her disposal, guided within the realms of her cognitive maps and imaginative routes. Her own critical thinking and her ability to judge and define the outcome of her creative work should derive from both subjective impressions and the comprehension of the critical reasoning embedded within the disciplinary principles of theoretical analysis. Imagination is not just linked to creativity, but also to critical judgment (Johnson, 1987).

The accumulation of knowledge, both intellectual and emotive, as well as their interpretation, can be regarded as the foundational material of the author's personal creative input into her work. As per Huhn's definition $(1968,5)$, "Creativity is the ability and initiative to create new ideas and/or things by the restructuring or redefining of past experiences into new forms". Similarly, Oatley $(2003,165)$ indicates that the synergetic process of perception and memory invocation equals the constructive projection of knowledge. As such, the creative process frequently referred to as 'inspiration' is in reality the result of a sequential and multidirectional course of the following stages: observation, perception, empathy and imagination.

Observation refers to an author's inclination to notice her surrounding world. The impressions of all such accumulated images will constitute the solid platform on which she will build her narrative. As Gardner $(1983,24)$ indicates, the novelist's task is to proffer "concrete images drawn from a careful observation", observation of people's behaviour imprinted in meticulous detail. Perception is reflected in her ability to be a participator at the same time, in 
order to comprehend and translate stimuli into meaningful occurrences. Lee Martin illustrates this point accordingly:

[F]iction writers are "spectators" of their characters, who are "participants" in the worlds of their stories - worlds that present situations containing their own demands for decision and action. If we imbue our fiction with aspects of ourselves - if we are ultimately both spectator and participant - it stands to reason that the key to learning something of ourselves and our worlds from the fiction we write lies in a successful merger of the two roles $(1998,173-174)$.

Empathy entails perceiving motives and desires that instigate choices and actions. It is precisely such capacity that allows authors to create believable anti-heroes and antagonists, even when reader allegiance is not possible due to cultural diversity and personal beliefs.

Finally, the interpreted scenes of daily life are not organised into sequential patterns, but rather are stored and rearranged in the writer's mind, either to emerge accidentally or be intentionally evoked in order to be transformed into new ones. Locations, idiosyncrasies and physiognomies will become disarranged and intermixed into textual constructs, modified and restructured by the author's perceptions. David Novitz (1987) considered fanciful imagination to be a prerequisite in the comprehension of one's environment:

[Fanciful imagination] plays an important role in adult attempts to decipher the more bewildering aspects of everyday life. For whenever established knowledge fails us, whenever there is no adequate conceptual apparatus with which to ease our confusion and bridge the gap between ignorance and insight, we fall back upon the fanciful imagination $(1987,32-33)$.

Novitz's theory essentially refers to an author's meta-perceptual activity, which entails translating united and dispersed images into logical sequences in order to decipher one's spatiotemporal surroundings. Subsequently, perception and fantasy are not to be rigidly viewed as two distinct functions, but often the former encompasses the latter (Watkins, 1999, 146). Moreover, fantasy and imagination do not serve to distort reality, but rather enhance or reshape it into different structures. In that respect, imagination is a contributor to knowledge, rather than its conceptual alternator. 


\section{The Character Delusion: Dispelling the Myth}

If the rendition of the real world through fiction is regarded as perceptively anthropocentric, analogously the epicentre of the narrative cosmos is the fictional character. It is this correlation between humans and fictional persons that places the author in such a unique position, for in principle she should be inherently predisposed to comprehend the essence of her subject. As Forster $(1974,54)$ noted, "Since the novelist is [her]self a human being, there is an affinity between [her] and [her] subject-matter which is absent in many other forms of art".

The novelist invents and discovers her characters through her experience of the human person. Invents, because every textual being is conceived ex nihilo; discovers, because her individual textual elements, both 'physical' and idiosyncratic, will emerge from the author's cognitive informational storage processed by her imagination. Put differently, the fictional agent is the creative conglomeration of all received data that constitutes the author's inspirational provisions. An author's ability to create a fictional character, from conception to textual exposition, is a process both inherent and consciously methodical at the same time.

Referring to the art of performing, Sonia Moore (1960) wrote:

Stanislavski realized that an actor has to learn anew to see and not just to pretend to see, to hear and not just to pretend to listen ... that he has to think and to feel. ... Stanislavski knew that an actor's mind, will and emotions - the three forces responsible for our psychological life - must participate in the creation of a live human being on stage (1960, 8-9).

Much like Stanislavski's actor, the novelist is called to conceive the most delicate threads of a new identity, and bring it alive, not on stage, but through her text. These three 'forces' will also aid her to create a convincing textual on paper. As Marisha Pessl (2008) explains,

[W]riting is a sort of acting exercise. You have to bring yourself and your own sensibility to your character, and yet you must diminish or augment certain aspects of yourself, see the world through their eyes, and judge the world according to their moral compass $(2008,38)$. 
The character becomes a separate entity, one the novelist is called to understand and follow. And yet such 'independence' is not always received well.

The contextual misinterpretation of the term 'real' more than often leads to unsubstantiated statements or even altogether rejections as 'exaggerations' or 'clichés' of the aforementioned creative process (Vermeule, 2000; Paris, 1999). But as Taylor, Hodges and Kohanyi (2003) elaborate,

In the positively-regarded context of creating writing, we are willing to accept the possibility of phenomenological peculiarities; we do not question the adult's mental health. Writers certainly become immersed in the fantasy world they create and, as they work, may lose track of their real-world surroundings, but we doubt that novelists are seriously confused about the fantasy/reality distinction (2003, 365-366).

It is a hypothetical, imaginary experience that takes place in the author's mind, one that will guide her to explore all possible paths of her character's cognitive map. Describing the mental process that renders the fictional character 'autonomous', Taylor et al. $(2003,366)$ introduce the concept of 'illusion of independent agency':

[T] he process of imagining the companion or the fictional world could become automatized until it is no longer consciously experienced. As the person readies him or herself for the imaginative act, the fantasy characters present themselves automatically. Their words and actions begin to be perceived, listened to, and recorded rather than consciously created. As a result, the imagined characters are experienced as speaking and acting independently $(2003,367)$.

The idea that all imaginary dialogues are symptomatic of psychopathology is refutable. A hypothetical interaction with a physically absent interlocutor should not automatically exclude the premeditation for such a process, depriving it from a conscious and specific purpose altogether. The fictional character is an inspired amalgamation of idiosyncratic attributes accumulated by a process of observation and comprehension of others, as well as thorough self-introspection. Subsequently, the symbolic soundless 'voices' of the characters speaking to the author emerge as variations of her cognition. Watkins (1999) explicates this as follows: 
[W]e shall define "Self" as the collection of different characters ... who can be said to populate an individual's thoughts, feelings, and actions. In other words, the Self is that world of characters whom one entertains and/or identifies with. ... Hence, when it is said that a dialogue is being carried out between self and imaginal other, the self here is the experiential locus of consciousness associated with the feeling of "I" $(1999,2)$.

Watkins (18-20) moves on to analyse Mead's account of children's fanciful play, according to which, such inner conversations contribute towards a realisation and determination of selfhood and society, through the adoption of alternative perspectives. Similarly, Keen $(2006,221)$ suggests that "[T]he activity of fiction-writing may cultivate novelists' role-taking skills and make them more habitually empathetic". Evidently, the theorists that dismiss the notion of 'imaginal' dialogues with characters as frivolous overlook this point precisely: that it is a premeditated, imaginary experience. Whether intentional or not, the de-centralisation of creativity and imagination as generators of such imaginal dialogues for the purpose of character germination, as well as the persistent contradistinction to a vague concept of reality, disorientates from the topic in question. The constant appeal to the delusion of influence bypasses the aforementioned point in its entirety.

Subsequently, the concept of character autonomy should not be examined outside the framework of a creative process. As Watkins (1999) indicates,

In using the term "autonomy" I make no claim that such characters exist in objectified nature, in and of themselves, independently of their being experienced. Nor do I mean that their apprehended qualities are independent of their relationship with a particular ego (1999, 105).

Moreover, the diversity of those hypothetical voices permits the author to exist in a perpetual exploration of material, assuming the role of both an observer and a participator. It is not simply the accumulated, incorporated data that is being kneaded; a semi-experiential discovery of new ones is also taking place. To quote Watkins $(1999,95)$ once more, "These articulations are not only aimed at establishing a rudimentary sense of self but are an ongoing 
and changing way of participating in the complex meanings and correlative definitions of se if and world".

Characters are a product of the author's ingenuity and can only exist dependently and interrelated to it; the author can be viewed to surrender to what Taylor et al (2003) have described as 'flow':

Flow refers to the pleasurable experience of becoming so totally absorbed in an activity that the sense of the passage of time is suspended, one loses track of the self and immediate surroundings, and the activity becomes effortless and unselfconscious. Authors often report the experience of flow while writing, as we suspect that flow might facilitate the development of autonomy in fictional characters $(2003,367)$.

The intentional interaction between the author and her characters is a process quite dissimilar to those experienced by persons with delusions or pathological conditions. To begin with, the latter are characterized by internal monologue (as opposed to imaginal dialogues), where the individual is sequentially usurped by a series of characters. This occurs outside of the self's awareness, and it is defined exactly by its singleness, not multiplicity (Watkins 1999, 107). Additionally, characterisation in such cases is superficial, enhancing only egocentric aspects that influence the 'I' (115); which comes into direct contrast with the creative writing act, where character-construction should be designated by multi-dimensionality and complexity.

\section{The Fictional Character: Towards a Definition}

In The Art of the Novel (1988), Kundera writes that,

All novels, of every age, are concerned with the enigma of the self. As soon as you create an imaginary being, a character, you are automatically confronted by the question: What is the self? How can the self be grasped? It is one of those fundamental questions on which the novel, as novel, is based $(1988,23)$.

The metaphysical implications of this question can be innumerable, and theories of personhood and the self inexhaustible. Different views have been held by various writers throughout the history of literature, and this is precisely where the creative attribution of each 
comes into the equation. With that in mind, I define character as "the textual object that encompasses the functions of initiating and reciprocating action within the narrative, thus weaving the thread of the plot" (Varotsi, 2014).

The nature of the correspondence between character and the real person is defined as much by the similarities between the two poles, as by their fundamental differences. Kundera himself $(1988,33-34)$ resists the idea that the fictional character is a simulation of a human being, but rather speaks of "an experimental self with an existential problem" - referring thus to the type of narrative Harvey $(1965,134)$ described as "the subjective novel".

Again emerges the pseudo-dilemma of the character can either be reduced to a summary of textual symbols, or is regarded as the simulation of a human being. Yet this is not an "either or' situation; a character is a textual construct, based on the experiential perception of a human being. She cannot have any true psychological dimensions, much like she cannot possess a real body, or exist in a real setting. She exists behind the textual cues, within the sphere of the author and reader's cognition and imagination. As such, she is identifiable in her isolated singularity. As Harvey (1965) remarked:

When, in real life, we try to describe a person's character we generally speak in terms of a discrete identity. We think of it as something unique and separable from all other identities. We do this, of course, because the most intimate sense of character we can possibly have - our knowledge of self - is of this kind. ... From this we extrapolate a similar sense of the characters of others; they may be private and unknowable but they are like us at least in this respect $(1965,31)$.

A character's actions matter only if the reader is able to fathom them, and this interpretation is based on the inherent understanding of the human person regardless of the concept's extent of deviation. Internal consistency ensures the external congruity of the narrative. Concsequently, the character can be viewed as a complex system of interrelated components in constant synergy and interaction (Varotsis, 2015). The character's attributed idiosyncrasy will instigate events, or reacted to them, initiating new events, forming and reforming relationships with other characters, and so on. The plausibility of the narrative will 
highly depend on the agent consistency, and understanding of choices and motivations, even if reader allegiance due to socio-cultural norms and beliefs is not feasible.

\section{Conclusions}

My aim has been to challenge the notion advocated by certain post-event analysis scholars, that any correlation between the fictional agent and its prototype, the human being, is unsophisticated or unscholarly. The use of language should not overshadow creative processes, but actually constitute a tool in their implementation. Furthermore, any attempt to disassociate empathy from cognition overlooks that the former is precisely an inseparable function of the latter. Keen's (2006) distinction between "empathy and sympathy" illustrates this point further. As she remarks (208), "In empathy, sometimes described as an emotion in its own right, we feel what we believe to be the emotions of others. ... Empathy is distinguished in both psychology and philosophy (though not in popular usage) from sympathy, in which feelings for another occur". Isolating emotion from reader-response equals overlooking the experiential part of a text's deconstruction.

As creative writing pedagogy is constantly enriched, the necessity for an exclusive theoretical framework to support the practice of writing becomes all the more evident. Any correlations between the narrative, the concepts of reality and the world, as well as the fictional agent and the human person, should be put under scrutiny. An investigation of conceptual liaisons, as well as a foundational definition of character and its constituent components as per Smith's (1995) person schema, is a solid step towards such a contribution. At the same time, ex novo creation and post-event analysis in synergy can enrich academia and industry, proffering further understanding to students and practitioners alike. 


\section{References}

Barthes, R. (1977) Image, Music, Text. London: Fontana Paperbacks.

Coetzee, J.M. (1999) Disgrace. Bath: Chivers Press.

Egri, L. (1960) The Art of Dramatic Writing. New York: Simon \& Schuster.

Forster, E.M. (1974) Aspects of the Novel. London: Arnold.

Gardner, J. (1983) The Art of Fiction: Notes on Craft for Young Writers. New York: Vintage Books.

Guildford, J.P. (1959) 'Three Faces of Intellect', American Psychologist, 14, pp. 469-479.

Hahn, M. (1968) Review of Research in Creativity. Minnesota: Minnesota Research Coordination Unit in Occupational Education.

Harvey, W.J. (1965) Character and the Novel. London: Chatto 7 Windus.

Johnson, M. (1987) Body in the mind. Chicago: The University of Chicago Press.

Keen, S. (2006) 'A Theory of Narrative Empathy’, Narrative, 14(3), pp. 207-236

King, S. (2000) On Writing. London: Hodder and Stoughton

Knights, L.C. (1973) How Many Children had Lady MacBeth. New York: Haskell House Publishers Ltd.

Kundera, M. (1988) The Art of the Novel. London: Faber \& Faber.

Mar. R.A. and Oatley, K. (2008) The Function of Fiction is the Abstraction and Simulation of Social Experience, Perspectives on Psychological Science, 3(3), pp. 173-192.

Martin, L. (1998) 'My Other, My Self: Participants and Spectators in Introductory Fiction Writing Workshops', in Starkey, D. (Ed), Teaching Writing Creatively. Portsmouth: Boynton/Cook Publishers, pp. 172-179.

McCann, G. (1993) 'Distant Voices, Real Lives: Authorship, Criticism, Responsibility', in Biriotti, M. and Miller, N. (eds.) What is an Author. Manchester and New York: Manchester University Press.

Moore, S. (1984) The Stanislavsky System. New York: Penguin.

Novitz, D. (1987) Knowledge, Fiction and Imagination. Philadelphia: Temple University Press.

O’Connor, F. (1972) Mystery \& Manners. London: Faber and Faber. 
Oatley, K. (2003) 'Writingandreading: The Future of Cognitive Poetics', in Steen, G.J. \& Garvins, J. (eds.) Cognitive Poetics in Practice, London: Routledge, pp. 161-173.

Paris, B. (1997) Imagined Human Beings: Psychological Approach to Character and Conflict in Literature. New York: New York University Press.

Pines, L.A. (1985) 'Toward a Taxonomy of Conceptual Relations and the Implications for the Evaluation of Cognitive Structures' in West, H.T.L and Pines, L.A., (eds) Cognitive Structure and Conceptual Change. New York: Academic Press Inc., pp. 101-116.

Scholes, R. and Kellogg, R. (1966) The Nature of Narrative. Oxford: Oxford University Press.

Seger, L. (1990) Creating Unforgettable Characters. New York: Henry Holt and Company.

Smith, M. (1995) Engaging Characters: Fiction, Emotion and the Cinema. Oxford: Oxford University Press.

Taylor, M., Hodges, S. and Kohanyi, A. (2003) 'The Illusion of Independent Agency: do Adults Fiction Writers Experience Their Characters as Having Minds of Their Own?' Imagination, Cognition and Personality, 22 (4), pp. 361-180.

Varotsi, L P (2014) Conceptualisation and Exposition: a Paradigm of Character Creation (Unpublished $\mathrm{PhD}$ thesis, University of Gloucestershire).

Varotsis, G. (2013) Screenplay and Narrative Theory: The Screenplectics Model of Modern Narrative Systems. Lanham: Lexington Books.

Vermeule, B. (2010) Why Do we Care about Literary Characters. Baltimore: The John Hopkins University Press.

Watkins, M. (1999) Invisible Guests. Putnam: Spring Publications. 